
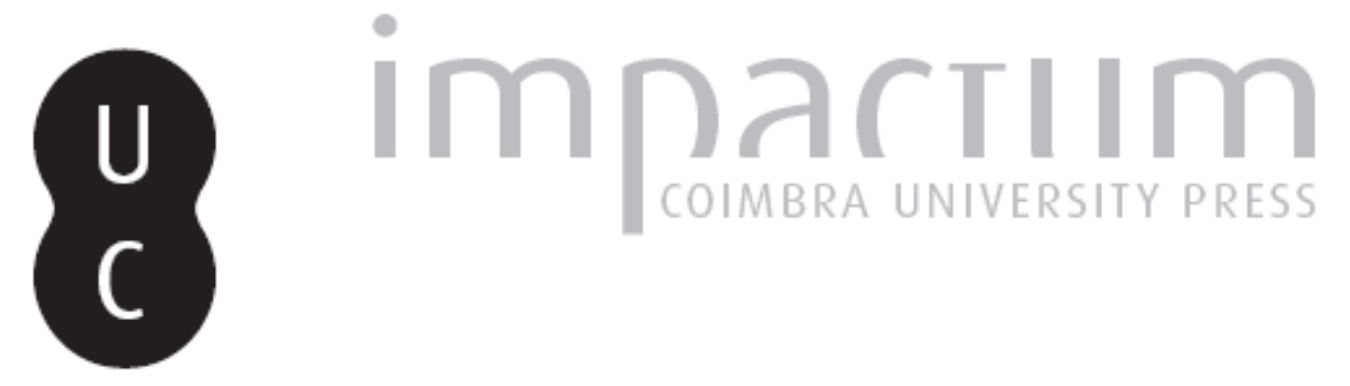

\title{
Pequenas notas de história antiga e epigrafia
}

Autor(es): Dias, Maria Manuela Alves

Publicado por: Imprensa da Universidade de Coimbra

URL persistente:

URI:http://hdl.handle.net/10316.2/45653

DOI:

DOI:https://dx.doi.org/10.14195/1647-8657_24_2

Accessed : $\quad$ 26-Apr-2023 09:52:45

A navegação consulta e descarregamento dos títulos inseridos nas Bibliotecas Digitais UC Digitalis, UC Pombalina e UC Impactum, pressupõem a aceitação plena e sem reservas dos Termos e Condições de Uso destas Bibliotecas Digitais, disponíveis em https://digitalis.uc.pt/pt-pt/termos.

Conforme exposto nos referidos Termos e Condições de Uso, o descarregamento de títulos de acesso restrito requer uma licença válida de autorização devendo o utilizador aceder ao(s) documento(s) a partir de um endereço de IP da instituição detentora da supramencionada licença.

Ao utilizador é apenas permitido o descarregamento para uso pessoal, pelo que o emprego do(s) título(s) descarregado(s) para outro fim, designadamente comercial, carece de autorização do respetivo autor ou editor da obra.

Na medida em que todas as obras da UC Digitalis se encontram protegidas pelo Código do Direito de Autor e Direitos Conexos e demais legislação aplicável, toda a cópia, parcial ou total, deste documento, nos casos em que é legalmente admitida, deverá conter ou fazer-se acompanhar por este aviso. 
FACULDADE DE LETRAS

INSTITUTO DE ARQUEOLOGIA

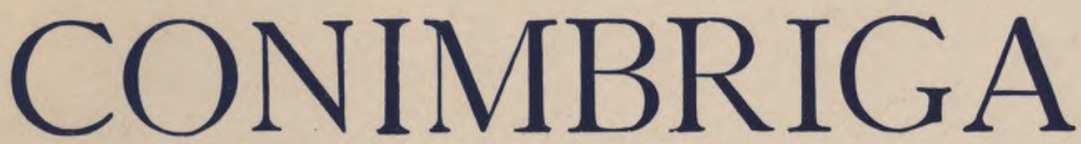

VOLUMEXXIV

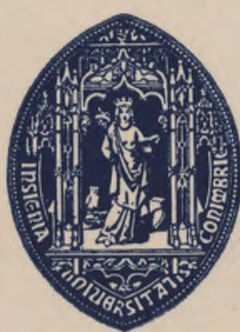

UNIVERSIDADE DE COIMBRA

1985 
Maria Manuela Alves Dias

Assistente convidada da Faculdade de Letras de Lisboa

PEQUENAS NOTAS DE HISTÓRIA ANTIGA E EPIGRAFIA

«Conimbriga», XXIV (1985), p. 85-95

Resumo: 1. Na sequência do artigo do Prof. Robert Étienne sobre o carré magique («Conimbriga», XVII, p. 15-34), a A. assinala a presença $\mathrm{de}$ palavras da fòrmula màgica (sator, tenet, opera, arepo) num documento do séc. xvm, ou mesmo do séc. xix, de um processo da Inquisição de Lisboa.

2. A inscrição funerária romana da Quinta da Macheia, Torres Vedras («Conimbriga», XXI, p. 42-49) apresenta urna forma ortográfica antiga de cuius; este pormenor reforça a correcção da cronologia proposta por V. G. Mantas para este epitáfio.

3. A propósito de um sinete falso, com os nomes consulares de 488 a.C., pertencente ao Museu de Évora, a A. analisa alguns problemas da falsificação de sinetes romanos e as dificuldades de verificação de autenticidade.

Résumé: 1. À la suite de l'article du Prof. Robert Étienne sur le carré magique («Conimbriga», XVII, p. 15-34), PA. signale la présence des mots de la formule magique (sator, tenet, opera, arepo, dans un document du XVIIIème/XIXème siècle d'un procès de l'Inquisition de Lisbonne.

2. L'inscription funéraire da Quinta da Macheia, Torres Vedras («Conimbriga», XXI, p. 42-49) présente une forme orthographique ancienne de cuius qui renforce la chronologie proposée par M. Mantas pour cet épitaphe.

3. A propos d'un sceau (avec les noms consulaires de l'année 488 av. J.-C.) du Musée d'Évora, l'A. analyse quelques problèmes de la falsification de sceaux sigili aires romains et les dificultés de vérification d'authenticité. 
(Página deixada propositadamente em branco) 


\section{PEQUENAS NOTAS DE HISTÓRIA ANTIGA E EPIGRAFIA}

\section{A fórmula rotas/sator e a sua sobrevivência cultural}

Recentemente, num excelente artigo publicado nesta revista $\left({ }^{\mathrm{x}}\right)$, foram analisadas as questões genéricas e os principais eixos da problemática actual do famoso carré magique, encontrado agora também em Conímbriga $\left({ }^{2}\right)$.

Entretanto, aparecia numa prova dum processo da Inquisição de Lisboa, guardado no Arquivo Nacional da Torre do Tombo, em Lisboa, um vestígio da sobrevivência cultural da fórmula mágica, datável dos últimos anos do século xvm, ou até mesmo dos dois ou três primeiros anos do século xix ( ${ }^{3}$ ).

Trata-se de um «pacto com o demónio», escrito com o sangue do pactuante e ilustrado com as figurações dum crucifixo, de armas, brancas e de fogo, de uma serpente alada, duma forca; uma mão-de-finado, um tambor, uma muralha, bombardas, elos duma cadeia metálica, uma edificação de dois pisos (igreja?) e um corpo feminino desnudo, bem como um cálice de ofício com um Menino Jesus saínte, completam a iconografia 'passiva ${ }^{5}$ ou $^{\text {estática }}{ }^{5}$, seja a que não exprime qualquer movimento, e cujo valor mágico, da sua própria natureza emblemática, é mais passível de interpretações categoriais diferentes. As restantes figurações, os 'retra-

P) Robert étienne, Le «carré magique» à Conímbriga (Portugal), «Conimbriga», XVII, Coimbra 1978, p. 15-34.

(2) Fouilles de Conimbriga, II, Épigraphie et sculpture, Paris 1977, p. 168-170; tijolo, com letra do séc I, encontrado «hors stratigraphie» em 1970 e guardado no Museu Monográfico de Conímbriga.

( $\left.{ }^{3}\right)$ [António J. R. Guerra], Pacto com o Demónio. Inquisição de Lisboa, Processo 14 649, de Matias Gonçalves Guizanda-Preto, preso em 1803, em Olinda, «História e Sociedade», 4-5, Lisboa 1979, doc. III. 
tos', são as de Diabos-maiores (que têm, aliás, os nomes expressos), Lúcifer, Satanás e Barzabú (Brazabul), e as de quatro Diabos-menores (aparentemente Diabos-menores, ou mesmo facanitos, se os não quisermos entender como 'feitiços ${ }^{5}$ ou como 'males ${ }^{5}$ ou como 'passos ${ }^{5}$ duma liturgia satânica), somando, portanto, os Sete-diabos; destes últimos, um deles é representado numa forma híbrida da mulher-leão, outro na forma dum galináceo, o galo; ora são estes, os Diabos-menores, que têm, precisamente, junto, como que a nomeá-los assim, as palavras da fórmula mágica: Satro (por sator), teneto (por tenet), Operas (por opera) e Arepo. Arepo é a única palavra que conserva a sua forma original tal qual; rotas encontra-se efectivamente ausente; as pequenas corruptelas populares que as outras palavras inscritas apresentam parecem-nos pouco significativas, no entanto, é curioso observar que, na sua 'viagem semântica ${ }^{5}$, chamemos-lhe assim, até este documento, as palavras da fórmula mágica tenderam para a nominalização, ou para o seu reforço, assim, acabou-se por 'substantivar ${ }^{5}$ o elemento verbal, tenet, que passou a teneto e que aqui aparece como que a nomear a ave, o galo; este mesmo elemento verbal é reconhecível na primeira palavra da curta locução de feitiço: «Tenato, ferrato, andato, passe por baixo», da tradição portuguesa, capítulo de bruxarias $\left({ }^{4}\right)$.

A longa viagem subterrânea do carré magique e os seus intensos e constantes contactos e interpenetrações com o mundo das superstições, do satânico e do maravilhoso documentam-se, pois, uma vez mais agora, com este vestígio português do Brasil colonial. Parece-nos também que, com ele, se acentua a importância de Portugal na rota da sobrevivência cultural do carré magique $\left(^{5}\right)$;

(4) A[ugusto] C[arlos] Teixeira de Aragão, Diabruras, santidades e prophecias, 2. ${ }^{\mathrm{a}}$ ed., Lisboa s/d, p. 39.

(5) Cf. [António Augusto da] Rocha Peixoto, A origem d'uma fórmula mágica, «PorlugáHa», II, Porto 1903, p. 628-629 e José LEITE DE VAsconcellos, Uma fórmula mágica, «O Archeólogo Português», XXIII, Lisboa 1918, p. 321-323. Sobre a continuidade da forma combinatória do carré magique em Portugal, no período barroco em poesia (c até numa tese de Direito Civil, de 1726) e a prática da sua imitação cf. AnA HatherLy, Labirintos portugueses dos séculos XVII e XVIII, «Colóquio-Artes», 45, Lisboa 1980, p. 20-29 e A. HатнеrLy, A experiência do prodígio, Lisboa 1983, p. $97-98$ e fig. 84 . 
apesar dessa facilmente reconhecível importância, será certamente prematuro admitir, por tal, que, no período tardorromano, teriam sido muito intensas e frequentes, na Lusitânia e no ocidente galaico, práticas mágicas deste tipo, ligadas a uma ou a outra das duas principais religiões de salvação que aqui nos chegaram talvez mesmo pouco depois do início do Império: o Mitraísmo e o Cristianismo $\left(^{6}\right)$; no entanto, será essa uma hipótese a que deve estar atento o historiador que lide com os microelementos culturais, religiosos e ideológicos mais persistentes da longá duração $\left(^{7}\right)$. Nota-se, ainda, que a sobrevivência cultural da fórmula rotas!sator que chega até nós, pelo menos até ao fim do século xix, se deu, aparentemente, à custa duma transferência, radical talvez, do campus social e cultural; trata-se, enfim, em poucas palavras, de uma forma de resistência do paganismo (ou dum cripto-judaísmo messiânico progressivamente, cada vez mais, de grupos sociais de baixíssimo relevo sócio-jurídico) no Mundo Ocidental medieval e moderno $\left({ }^{8}\right)$.

$\left.{ }^{6}\right)$ Há, como se sabe, duas teses essenciais: a numérica que associa o carrê magique ao Mitraísmo, cf. Whater O. Moenter, The mithraic origin and meaning of the Rotas-Sator square, Leiden 1973, e a que o associa ao Cristianismo primitivo, cf. Jéróme carcopino, Les fouilles de Saint-Pierre et la tradition. Le Christianisme sécret du carré magique, Paris 1963, p. 12-112; a questão pôs-se a partir de 1934 com as escavações de Dura-Europos dirigidas por M. Rostovtzeff, cf. R. Étienne, op. cit., p. 17-18; sobre a coexistência das práticas mitraicas e cristãs em Dura-Europos, na fronteira do Império com os Partos, na Síria, cf. M. Rostovtzeff, Dura-Europos and its Art, Oxford 1938; muito mais recentemente, Paul Veyne, na esteira de G. A. de Jerphanion, sustenta o primado do carácter lúdico sobre o mágico do carré magique, cf. R. É TIENNe, op. cit., p. 25-34.

(7) $\mathrm{Na}$ acepção braudeliana, evidentemente; cf. FERnANd BRAUdel, Écrits sur VHistoire, Paris 1969, p. 11-85.

$\left.{ }^{8}\right)$ Mesmo se o carré magique for entendido originariamente como um produto judaico, anterior ao Cristianismo, e que tenha acompanhado subterraneamente a diáspora israelita, cf. MARCEL Simon, Verus Israel: Etude sur les relations entre Chrétiens et Juifs dans VEmpire Romain, Paris 1964, p. 410-413. Aliás, o 'quadrado' é uma forma que, no séc. i d.C., pertencerá à simbologia profética da 'redução' de Israel e do seu povo, cf. JosePH., Réll. Judaic., YI.V.4: 311 e Stanislas Giet, VApocalypse et VHistoire - Etude historique sur VApocalypse johannique, Paris 1957, p. 13 e 38. 


\section{Forma pronominal antiga numa inscrição de Torres Vedras}

A inscrição funerária da Quinta da Macheia (freguesia de Matacães, concelho de Torres Vedras), recentemente publicada, de novo, nesta revista $\left({ }^{9}\right)$ apresenta uma forma pronominal, quius (1. 6), que se pode considerar, ortográfica e morfologicamente, intermédia entre a arcaica, quoios, e a clássica, cuius $\left({ }^{10}\right)$.

De facto, a forma quius (genitivo singular uniforme de qui, quae, quod) que poderíamos chamar talvez tardo-republicana, terá 'sucedido ${ }^{5}$, em Roma $\left({ }^{\mathrm{n}}\right)$, à forma arcaica quoios $\left({ }^{12}\right)$ e parece que perdurou, na Hispânia $\left({ }^{13}\right)$, em contraponto de resistência à forma 'clássica ${ }^{5}$, nova, cuius.

Certamente que nem todas as situações em que, nas inscrições romanas da Hispânia, um $q$ aparece em lugar dum c, podem

(9) Vasco Gil Mantas, Inscrições romanas do Museu Municipal de Torres Vedras, «Conimbriga», XXI, Coimbra 1982, p. 42-49: Licinia P(ublii) f(ilia) Maxs/uma $M$ (arcus) Antisti/us M(arci) f(ilius) Gal(eria tribu) Facund/us h(ic) s(iti) s(unt) $/ 5$ Cornelia: T(iti) f(ilia) Boutiaj quius posita est/ in prima parte ima/go viva se f(aciendum) c(uravit). Trata-se da primeira publicação cuidada desta inscrição, integrada, aliás, numa publicação extensa (p. 5-99), onde se estudam treze inscrições funerárias romanas, todas elas importantes para o conhecimento histórico da romanização no território noroeste do aro de Felicitas Iulia Olisipo, no Conventus Scallabitanus. Traz a bibliografia anterior.

${ }^{10}$ Cf., v. g., B. L. Gildersleeye and G. Lodge, Latin grammar, 3th ed. London 1965, p. 59 e L. R. Palmer, The latin language, London 1966, p. 255. V. tb. Alfred ernout, Morphologie historique du latin, Paris 1953, p. 86-87.

(n) Cf. C1L, I, 2, 1297 (= CIL, VI, 16 614), Ultuma / suorum / Cupieinnia / L(ucii) f(ilia) Tertulia /5 fuveit quius / heic / relliquiae / suprema / manent, de Roma.

(12) Cf., v. g., CIL, I, 2, 6-7 (há uma fotografia desta inscrição tumular em A. H. McDonald, Roma Republicana, trad, da ed. ingl., Lisboa 1971, fot. 4 e capa) e 1206 ; v. tb., (para quoi), C. J. FordyCE, Catullus: a commentary, Oxford 1961, p. 3 e 84.

(13) Cf. CIL, II, 1964 (Lex Malacitana, LVI, 1. 46, quiiusque)', há um comentário jurídico ao passo, onde se inclui esta forma, em Álvaro d'Ors, Epigrafía jurídica de la España romana, Madrid 1953, p. 320-321. Emil Hübner, em CIL, II, 2 601, inscrição votiva da Galiza dedicada a Navia, desenvolveu a última linha da inscrição em: q(uoios) e(um) c(ompotem) f(ecit); parece-nos agora que um desenvolvimento em q(uius), etc., seria talvez mais consentâneo. 
ser entendidas como indícios de arcaísmo no latim usado, ou, pelo menos, na sua ortografia. Além dos exemplos já indicados (n. 13), como indicio de arcaísmo, temos, em inscrições peninsulares, o uso de $q$ em vez de c, seguramente apenas nas seguintes duas palavras: qum( $\left.{ }^{u}\right)$ e pequnia( $\left.{ }^{15}\right)$.

Assim a forma, digamos, 'antiga ${ }^{5}$, de quius, reforça a correcção da datação proposta por V. G. Mantas $\left({ }^{16}\right)$.

É de notar também a importância de ter sido encontrado, precisamente no ocidente da Lusitânia, este exemplo republicanizante dum genitivo pronominal que, como se sabe, estaria, então, a originar o adjectivo cuius, cuia, cuium que teve um destino próprio nas línguas românicas peninsulares $\left({ }^{17}\right)$.

No caso desta inscrição, tão bem caracterizada, é de excluir ainda, a qualquer título, a hipótese de se tratar de um erro do lapicida, do ordinator ou do scriptor $\left({ }^{18}\right)$.

(14) CIL, 1222 e 2215.

(16) CIL, II, 2041 e 3421; para esta forma cf. A. Ernout, Recueil de textes latins archaiques, Paris, 1966, p. 80, 81, 86, 90, 96 e 97 o E. H. Warmington, Remains of old latín, IV, Archaic inscriptions, London 1940, p. 180 c 190.

(17) V. G. Mantas, op.cit., p. 49.

(17) Cf. antonio Tovar, Latin de Hispania: aspectos léxicos de la romanización, Madrid 1968, p. 25: «Por ejemplo, cuyo, vivo hasta por lo menos ayer en nuestra lengua, se encuentra en la literatura de los siglos de la conquista, en Plauto, en Terencio, en Lucilio (Neue-Wagener, Formenlehre der lateinischen Sprache, II, 471 y sig.): cuius, cuia, cuium, nos dice uno de los más recientes tratadistas del latín vulgar (V. Váánánen, Introducción al latín vulgar, trad, esp., Madrid 1967, 20), «reaparece apenas en Virgilio y Cicerón en contextos particulares y hace pensar que es arcaísmo. Pero el testimonio de las lenguas románicas (log. kuyu, esp. cuyo, port, cujo) devuelve a esta palabra la vida que los monumentos escritos le niegan (la geografía hace inaceptable la difusión de la palabra cuius a consequência del uso de Virgilio como texto en las escuelas, según propone Mariner, ELH, I, 204). Había quedado viva, podemos precisar, en las provincias de colonización más antigua, pero en Roma era un arcaísmo, un rusticismo que sabemos que los literatos de la época le echaron en cara a Virgilio cuando la usó en boca de uno de sus pastores»». $\mid E L H=$ Enciclopedia Lingüistica Hispánica, Madrid 1960 e ss.].

$\left.{ }^{18}\right)$ Para os erros palcográficos e ortográficos frequentes na epigrafía latina v., v. g., Giancarlo SuSINi, The roman stonecutter (trad, da ed. ital. de 1967), Oxford 1973, p. 39-49. 


\section{Um 'falso' do Museu de Évora}

No verão de 1980, a Dr. ${ }^{a}$ Alice Lamy Tavares-Chicó, então Directora do Museu de Évora, mostrou-nos um sinete em bronze, existente neste museu sem indicação de procedência e de cuja autenticidade duvidava.

Efectivamente, quanto a nós, trata-se dum objecto falso; basta atentar na forma paleográfica do $T$ da 1.1 para afirmá-lo.

É, no entanto, curioso assinalar que esta falsificação se apoiou, talvez para ter um curso comercial seguro, na veracidade histórica, e até facilmente comprovável, dos nomes consulares expressos: Sp(urius) Nau(tius) Rutilus e Sex(tus) Fur(ius) Fussus são, nada mais nada menos, que os cônsules do ano 488 a.C. (=266 ab urb. cond.) (19).

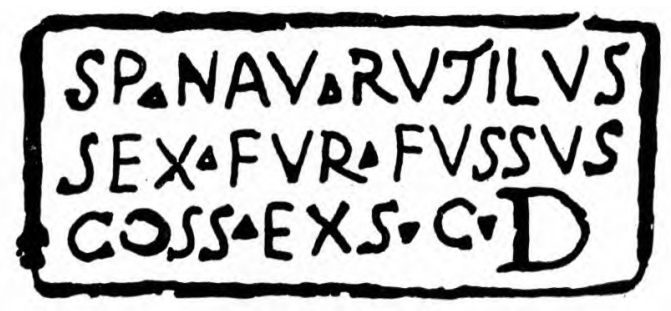

Como, quanto pudemos averiguar, este par consular nunca foi referido por qualquer autor clássico, creio que temos de considerar este 'falso' como um produto do comércio turístico contemporâneo (desde o $3 .^{\circ}$ quartel do séc. xix aos nossos dias) e não como uma falsificação antiga destinada aos coleccionadores e amadores de realia, dos séc. xvi, xvn e xvm; não se trata, contudo, da 'reprodução' de um objecto verdadeiro (o alfabeto e a morfologia usados, p. e., Fur(ius) e não Fourios, são impensáveis no séc. v a.C.), mas sim duma composição totalmente inventada a partir duma referência consular dos Fasti Capitolini.

(19) Cf. CIL, I, 2, p. 1-181; sobre ambos V. Jean-Claude Richard, Les origines de la plèbe romaine. Essai sur la formation du dualisme patricio-plébéien, Paris-Roma 1978, p. 536-537; sobre a importância social das suas famílias V. Roвert E. A. Palmer, The archaic community of the Romans, Cambridge 1970, p. 249-250, 258-259, 290-291 c 297-298. É possível que Sex. Furius Fussus (aliás, Fusus) tenha também usado o cognome Medullinus. 
A verificação da autenticidade da documentação epigráfica, que mereceu já, entre nós, artigos interessantes $\left({ }^{20}\right)$, é uma tarefa primordial e indispensável ainda que muito trabalhosa e, por vezes, delicada — frequentemente assentará apenas na análise combinada de omissões, de dúvidas e de raras certezas.

Veja-se o caso de um outro sinete, pertencente ao Gabinete de Numismática e Antiguidades da Biblioteca Nacional, Lisboa $\left({ }^{21}\right)$, que Emil Hübner inclui no $C$. /. L., II (22). Ora, por o nome inscrito neste sinete, L. Valerius Flaccus, ser um dos nomes conhecidos da história da romanização peninsular $\left({ }^{23}\right)$ parece que seria caso para ter perfeito cabimento uma fortíssima suspeita de este sinete não ser senão uma falsificação, talvez dos sécs. xvi ou xvn; veremos que não. Acontece que a família dos Valerii Flacci (onde o praenomen L(ucius) parece ter sido o mais frequente) foi uma das mais importantes da nobreza romana dos três últimos séculos da República, tendo participado activamente no processo expansionista de Roma e, durante oito sucessivas gerações, de 261 a 86 a.C., membros seus terem ocupado, por oito vezes, o consulado $(24)$. Durante 215 anos os numerosos elementos desta família

(20) Com relevo para José D'ENCARnaÇão, Autenticidade em epigrafia: as inscrições de Cuba e Vila Nova de Baronia, "Arquivo de Beja», XXVIII-XXXII, Beja 1971-1975, p. 57-62.

(21) Jorge Alarcão e Manuela delgado, Catálogo do Gabinete de Numismática e Antiguidades. 7. ${ }^{\mathrm{a}}$ parte: Antiguidades ibéricas e romanas, Lisboa 1969, p. 32-33.

(22) CIL, II, 4975, 64; L. V. FLAC. - L(ucius) V(alerius) Flac(cus); porque precisamente se trata dum conjunto onomástico estável e conhecido, não é admissível outro desenvolvimento para o nome gentilicio; o desenvolvimento do cognome cm hipotéticos derivados, como Flac(c)illus ou Flaccinus, parece-nos um artifício despropositado, até porque, se fosse esse o caso real, o natural seria que se não apresentasse o cognome sob uma forma abreviada equívoca.

(23) Cf. Cic., p. Flacc., 5 e 6 e Cass. Dio, 36, 54. Seu tio, C. Valerius Flaccus, ainda foi mais conhecido na Península Ibérica, cf. ApP., b. c., 1, 89, e Gran. Licinian.: «... et Murena ex Asia triumphavit et Valerius Flaccus ex Celtiberia...)).

(24) A 'dinastia consular' dos Valerii Flacci é a seguinte: $1 .^{\circ}$, L. Valerius Flaccus, consul em 261 a.C. com T. Otacilius Crassus; 2. ${ }^{\circ}$, P. Valerius Flaccus (filho do anterior), consul em 227 a.C. com M. Atilius Regulus; 3. ${ }^{\circ}$, L. Valerius Flaccus (filho do anterior), consul em 195 a.C. com M. Porcius 
patrícia dos Valerii (cujos dois principais ramos, os Valerii Flacci e os Valerii Messallae tiveram um destino político e social diferente) ocuparam a ribalta política como associados principais dos grandes «líderes»: M. Pórcio Catão, Sexto Mário, Sila, Pompeu, César. Para os Valerii Flacci, esta gigantesca aventura de seguidismo político (que provavelmente radicava na necessidade de sobrevivência dos privilégios originários da antiga situação oligárquica desta família) vai terminar em 48 a.C., com a morte, em Dyrrhachium, de C. Valerius Flaccus, o último grande representante da família e que, à data, era um declarado apoiante de Pompeu; compreensivelmente, logo, a importância política e social dos Valerii Flacii se abate e desaparece (25); contudo, o antigo prestígio do seu nome, multiplicado no dos seus liberti e outros dependentes, fará com que este sobreviva, dando-se, é claro, uma vulgarização do mesmo, um pouco por todo o Império e com alguma incidência na Península Ibérica (26). É por isto que, hermeneuticamente, quanto a nós, a suspeita de falsificação, no

Cato; 4. ${ }^{\circ}$, L. Valerius Flaccus (filho do anterior), cônsul em 152 a.C. com M. Claudius Marcellus; 5. ${ }^{\circ}$, L. Valerius Flaccus (filho do anterior), consul em 131 a.G. com P. Licinius Crassus Mucianus; 6. ${ }^{\circ}$, L. Valerius Flaccus (filho do anterior), consul em 100 a.C. com C. Marius; 7. ${ }^{\circ}$, C. Valerius Flaccus (neto do $4 .^{\circ}$ e primo-co-irmão do anterior), consul em 93 a.C. com M. Herennius; $8 .^{\circ}$, L. Valerius Flaccus (irmão do anterior) consul sufeta em 86 a.C.

$(25)$ Cf. Léonie Hayne, The Valerii Flacci - A family in decline, «Ancient Society», 9, Leuven 1978, p, 223-233. Os Valerii Messallae mais ou menos integrados na política de Augusto estarão representados no consulado em 31, 12 e 3 a.C. e 5 e 20 d.C., onde depois só regressarão muito mais tarde, e noutras condições, no final do séc. II, em 196.

(26) Sobre a extensão e vulgarização do nome e cognome, e do cognome só, cf. Iiro Kajanto, The Latin Cognomina, Helsinki 1965, p. 240; na Hispânia, entre outros possíveis, indiquemos o nome de Publius Valerius Publii filius Galeria tribu Valerianus Flaccus, Álvaro D'Ors y RAFAeL Contreras de LA Paz, Nuevas inscripciones romanas de Castulo, "Archivo Español de Arqueología», XXIX, Madrid 1956, p. 122-124, e o de Caius Valerius Flacci filius Quirina tribu Flaccinus, D. Fernando de Almeida, Egitània - História e Arqueologia, Lisboa 1956, p. 228-229; a vulgarização do cognome teve um dos seus centros precisamente aqui na civitas Igaeditanorum: Flaccus Calaeti filius, ID., ibid., p. 170-171, Flaccus Tongi filius, 
caso do sinete da Biblioteca Nacional, não pode ser senão muito ténue.

Quando, na verificação de autenticidade, não se pode contar com métodos laboratoriais seguros, associados a uma firme e rigorosa análise formal, e na ausência, de todo em todo, de registos de achado, resta apenas o recurso à teia conjectural que, forçosamente, resulta sempre de natureza aproximativa.

ID., ibid., p. 193 e outros mais, ainda bem dentro da Celtibéria temos o exemplo de CIL, II, 907, um Flaccus Arnbati; Flaccus é também o nome que aparece numa marca de oleiro de terra sigillata hispânica conhecida em Conímbriga, Setúbal, Yaiamonte, Torre de Palma, Alcácer do Sal, Tarragona, Lixus, Volubilis, etc., cf., v. g., Luísa Ferrer Dias, As marcas de "terra sigillata» do castelo de Alcácer do Sal, «Setúbal Arqueológica», IV, Setúbal 1978, p. 151 (com indicação de bibliografia anterior). 